\title{
Job Crafting by Students who Work and Study
}

\author{
Peter A. Creed ${ }^{1}$, Michelle Hood ${ }^{1}$, and Shi $\mathrm{Hu}^{2}$ \\ ${ }^{1}$ School of Applied Psychology, Griffith University, Australia \\ ${ }^{2}$ School of Education Science, Nanjing Normal University, China
}

Cite paper as: Creed, P. A., Hood, M., \& Shi, H. (2019). Job crafting by students who work and study. International Journal for Educational and Vocational Guidance.

doi:10.1007/s10775-019-09406-2

\begin{abstract}
Informed by a self-regulatory perspective, we tested a model $(N=233)$ in which job (e.g., autonomy), person (e.g., motivation), and study characteristics (e.g., engagement) predicted student job crafting, which, in turn, predicted work-study conflict and facilitation. Job, person, and study characteristics predicted task (46\% of variance), cognitive (56\%), and relational crafting $(25 \%)$, and cognitive and relational crafting predicted greater work-study facilitation (53\%). When students proactively modify their work environment, this is likely to assist them at work as well as facilitate their study life. Developing job crafting skills in students should improve both work and study functioning.
\end{abstract}

Keywords: Job crafting; job demands/resources, study engagement, work-study conflict, work-study facilitation, self-regulation 


\section{Job Crafting by Students who Work and Study}

There is a growing trend for tertiary students to work in paid employment while they undertake their studies (Vossensteyn et al., 2015). This trend is driven largely by the need for students to cover education costs and living expenses associated with tertiary study, as governments reduce their financial contributions and increase the costs associated with study (Devlin, James, \& Grigg, 2008). Students do benefit from paid work experience through skill development and increased financial security (Curtis \& Shani, 2002), but also are affected by reduced academic engagement and poorer well-being (Creed, French, \& Hood, 2015), and student retention and academic success also decline (e.g., students working $>8$ hours per week are more likely to drop out of study; Polidano \& Zakirova, 2011).

In Australia, about $80 \%$ of tertiary students work while studying (average 13-15 hours per week; Lingard, 2012), which is the second highest rate among OECD countries (Quintini, 2015). They work in a wide range of mostly service jobs, including retail, hospitality, tourism, agriculture, telemarketing, clerical roles, and tutoring (Australian Government, 2018). How successful students are at managing their competing roles of work and study affects their short-term achievements and well-being as well as their later careers and lives, and there are financial costs to individuals and families and lost government taxes when students fail to complete their education (Geel \& Backes-Gellner, 2012). About one in four Australian university enrolments fails to reach graduation (OECD, 2008).

Student employees, like full-time, adult employees, can be expected to manage their job pressures in the context of non-work responsibilities (e.g., study, family), while at the same time strive to make their work more interesting and fulfilling (Tims, Bakker, \& Derks, 2012). Organisations implement (top-down) strategies to facilitate employee motivation and performance (Aust, Rugulies, Finken, \& Jensen, 2010), but also often tolerate, and even 
encourage, employees to modify their job tasks and environment (bottom-up) to improve outcomes and conditions. Employees do this by modifying their mandated work tasks, initiating changes in their workplace social interactions, and by adjusting their work attitudes (Slemp \& Vella-Brodrick, 2013; Wrzesniewski \& Dutton, 2001). These adjustments to job tasks, relationships, and work attitudes are considered to be "job crafting". Job crafting addresses the demands inherent in the work (e.g., by increasing or reducing job challenge), expands the resources available to the individual (e.g., by increasing support from colleagues), and changes the way work is viewed (e.g., by finding meaning in the job), all of which are aimed at meeting individual needs and improving person-job fit (Bakker \& Demerouti, 2007; Wrzesniewski \& Dutton, 2001). Job crafting also benefits individuals outside of the work role; for example, by improving work/non-work life balance (Ilies, Pater, Lim, \& Binnewies, 2012). The current study tested a model of the antecedents to, and outcomes of, job crafting for working students (see Figure 1).

\section{Job crafting}

Job crafting is a self-regulatory response generated to reduce perceived gaps between the actual and desired work situations (Lord, Diefendorff, Schmidt, \& Hall, 2010). The central self-regulatory assumption is that people exert control over their situation and life direction (i.e., express agency) by setting goals and modifying behaviours when environmental feedback indicates that there is a discrepancy between what they would like and what currently exists (Bandura, 1991). Reducing discrepancies is important as this improves satisfaction and feelings of wellbeing.

Wrzesniewski and Dutton (2001) proposed that people job craft to increase control over their job, improve connections with others, and enhance their self-image. Others have argued that crafting is driven primarily by workplace imperatives, such as meeting workplace 
demands and increasing job resources (Bakker \& Demerouti, 2008; Le Blanc, Demerouti, \& Bakker, 2017; Slemp, Kern, \& Vella-Brodrick, 2015); while some have proposed that nonwork considerations (e.g., study, family) are also important (Demerouti, 2014; Ilies et al., 2012). Whatever the trigger, the primary focus is to meet the needs of the individual by reducing job-person misfit and improving satisfaction and functioning (Bakker \& Demerouti, 2008; Wrzesniewski \& Dutton, 2001).

Empirical evidence supports that both job (e.g., job demands, autonomy, support; Kanten, 2014; Petrou, Demerouti, \& Xanthopoulou, 2016) and person characteristics (e.g., proactivity, self-efficacy; Bakker, Tims, \& Derks, 2012; Tims, Bakker, \& Derks, 2014) are precursors to job crafting (for reviews, see Rudolph, Katz, Lavigne, \& Zacher, 2017; Wang, Demerouti, \& Bakker, 2016). It also is clear that crafting can be activated by factors external to the workplace, such as improving work-life balance (Sturges, 2012), expanding a calling (Berg, Grant, \& Johnson, 2012), facilitating successful aging, and deferring retirement (Kooij, Tims, \& Kanfer, 2015).

We assessed job, person, and the non-work (i.e., study-related) characteristics as antecedents to student job crafting (Figure 1), as these are associated with job crafting in fulltime employed adults (Rudolph et al., 2017; Wang et al., 2016), but have not been tested with working students. The job characteristics assessed were job demands, job autonomy, workplace support, and workplace culture; the person variable was the student's motivation for the job; and the non-work (i.e. study) characteristics were study engagement and the student's study-related mood.

Job demands stimulate self-regulatory crafting, as demands thwart achievement and generate frustration and dissatisfaction, while job resources, such as autonomy, support, and a positive culture, sustain a climate in which job crafting is tolerated or encouraged (Slemp et 
al., 2015). Person variables are important as they affect the appraisal of environmental influences and determine what responses are made to perceived or actual challenges (Bakker \& Demerouti, 2007; Lord et al., 2010). Non-job motivators also drive job crafting, as experiences away from work affect and are affected by what occurs on the job (Demerouti, 2014; Ilies et al., 2012); for example, unfavourable university experiences might motivate students to actualise desired states in another domain (Petrou \& Bakker, 2016).

Thus, when work conditions are unfavourable, student workers will seek ways to improve their job situation by modifying their job tasks, altering their social interactions at work, and/or adjusting their attributions about work. They will engage differently depending on the demands experienced and the job and person resources available. While these efforts can be positive, negative, or neutral for the organisation, the strived-for outcomes will be to meet individual needs and generate a better person-situation fit. Based on this, our first hypotheses were that job (i.e., demands, autonomy, support, and culture; Hypothesis 1a), person (i.e., motivation; Hypothesis 1 b), and study characteristics (i.e., engagement and affect; Hypothesis 1c) are related positively to job crafting.

\section{Work-to-study conflict and facilitation}

Work-to-study conflict and facilitation were tested as outcomes as they have important consequences for students. Work-to-study conflict refers to when participation in the work role negatively affects participation in the study role (Peeters, Wattez, Demerouti, \& de Regt, 2009). This is based on depletion theory (Greenhaus \& Powell, 2006), which states that different life roles compete for scarce resources and that resource expenditure in one role reduces resources available for another role. On the other hand, facilitation theory proposes that individual resources can be enhanced so that capital developed in one role can be applied in another; for example, interpersonal skills learned at work can facilitate better study 
outcomes (Greenhaus \& Powell, 2006). Role conflict/facilitation theories have been tested primarily in the work/family domains (Michel, Kotrba, Mitchelson, Clark, \& Baltes, 2011), although researchers have examined conflict/facilitation between work and other domains, such as civic engagement, religion, and leisure (Lin, Huang, Yang, \& Chiang, 2014).

Role conflict is associated negatively with well-being (Creed et al., 2015; Giancola, Grawitch, \& Borchert, 2009; Park \& Sprung, 2013) and sleep quality, and positively with fatigue (Park \& Sprung, 2015) and alcohol consumption in college students (Butler, Dodge, $\&$ Faurote, 2010). It is also related to poorer academic effort (Butler, 2007), attendance (McNall \& Michel, 2011), and GPA (Sy, 2006). Facilitation is related to better effort, attendance (Butler, 2007), GPA (McNall \& Michel, 2011), well-being, and engagement (Creed et al., 2015). This suggests that study activities are impeded, and well-being reduced, by work-study conflict, and conversely, students benefit when work generates resources that can be applied to study.

Several job and person characteristics have been tested as antecedents to work-study conflict. Job characteristics include hours worked (Creed et al., 2015), job demands (Butler et al., 2010), job control (Wyland, Lester, Ehrhardt, \& Standifer, 2016), work-place support (Adebayo, 2006; Park \& Sprung, 2013), and role overload (Singla, 2013). Person characteristics tested include job dissatisfaction (Taylor, Lekes, Gagnon, Kwan, \& Koestner, 2012), negative affect (Giancola et al., 2009), core self-evaluations (McNall \& Michel, 2011), proactivity (Adebayo, Sunmola, \& Udegbe, 2008), self-efficacy (Lingard, 2007), and job motivation (Derous \& Ryan, 2008). Additionally, some study-related variables have also been shown to influence work-study conflict, such as satisfaction with university life (Creed et al., 2015) and study demands (Wyland et al., 2016). 
Job characteristics related to work-study facilitation include job-related demands, control (Wyland et al., 2016), performance (McNall \& Michel, 2011), resources (Creed et al., 2015), involvement (Singla, 2013), and supervisor support (Wyland et al., 2016). Person resources include job satisfaction (Park \& Sprung, 2013), core self-evaluations, and proactivity (McNall \& Michel, 2011). Study-related variables are college engagement (Wyland et al., 2016) and adjustment (Singla, 2013). The converging evidence is that higher job and study demands, fewer job and study resources, and poorer personal resources are related to more study disruption from the competing work role (i.e., work-study conflict); and, conversely, more manageable demands, better resources, and stronger personal assets are related to less work-study disruption (i.e., work-study facilitation). These conclusions are consistent with meta-analyses and reviews examining conflict/facilitation in the work/family domains (Michel et al., 2011).

Few studies have directly tested the relationships between job crafting and role conflict/facilitation. Sturges (2012) used interviews to examine how young professionals crafted their jobs to achieve a better work-life balance and found that all participants reported using some type of job crafting to enhance both work and non-work roles. Akkermans and Tims (2017) tested the relationship between job crafting and work-home conflict/facilitation, and found positive associations for facilitation, but no relationship for conflict. We found one study (Sekiguchi, 2012) that investigated job crafting in working students, finding that both job (e.g., skill variety, autonomy) and person characteristics (e.g., job commitment, selfefficacy) were related to job crafting, but that crafting was unrelated to academic attendance or achievement. Thus, while there is theoretical support and some evidence that employees job craft to improve work/non-work relationships, this area is under-researched. Further, no studies have specifically examined how students job craft to facilitate their study or reduce 
work-study conflict. As every worker can potentially job craft (Tims et al., 2012), working students should also engage in these activities to benefit both their work and study roles. Our hypotheses here were that job crafting is related negatively to work-study conflict (Hypothesis 2a) and positively to work-study facilitation (Hypothesis 2b).

Consistent with self-regulation theories (Bandura, 1991) and job crafting perspectives (Bakker \& Demerouti, 2008; Wrzesniewski \& Dutton, 2001), job crafting is triggered by work and non-work demands and facilitated by work and non-work resources to improve work and life fit. Job crafting, thus, can be expected to mediate between job, non-job, and person factors and work-study conflict/facilitation. There is empirical support for the mediated relationships, although this evidence comes largely from studies with adults (Rudolph et al., 2017; Wang et al., 2016), as little is known about job crafting in working students. We expected that job crafting would mediate between job, person, and study characteristics and the outcomes of work-study conflict/facilitation (Hypothesis 3). We assessed three dimensions of job crafting - task, relational, cognitive (Wrzesniewski \& Dutton, 2001). However, as few studies have tested the relative effects of job, person, and extraneous work variables on these three dimensions (Rudolph et al., 2017), and no study has evaluated the differential relationships with work/non-work conflict and facilitation, our analyses here are exploratory.

\section{Method}

\section{Participants}

Participants were 233 undergraduate students (66\% female; $M_{\text {Age }} 20$ years, $S D$ 6.5) from one regional university in SE Queensland, Australia. For their final high school grade, 64 (28\%) reported "very high achievement", 117 (50\%) "high achievement", and 52 (22\%) “average” achievement ( $M_{\text {Ach }} 1.97, S D$ 0.75). For socio-economic status (SES), 16 (7\%) 
indicated being "much better off than others", 58 (25\%) "a little better off", 110 (47\%) "about the same", $38(16 \%)$ "a little worse off", and $11(5 \%)$ "much worse off" (MSES 2.87 , $S D$ 0.93). Finally, average hours worked per week were 16.33 ( $S D$ 7.27; range 3-48 hours).

\section{Measures}

Job Crafting. The 15-item Job Crafting Questionnaire (Slemp \& Vella-Brodrick, 2014) assesses the three job crafting processes assessed in the study: task crafting, relational crafting, and cognitive crafting. The three subscales each contained five items. Sample items were "Give preference to work tasks that suit your skills or interests" (task crafting), "Make an effort to get to know people well at work" (relational crafting), and "Think about how your job gives your life purpose" (cognitive crafting). Responses were made on a 6-point scale (1 hardly ever to 6 very often). The authors reported internal reliabilities (Cronbach's alphas) of $.87, .89$, and .83 , respectively, demonstrated a 3 -factor structure using both exploratory (EFA) and confirmatory factor analyses (CFA), and supported validity by finding expected associations with proactive work behaviours and well-being. Our alphas were .73, .80 , and .85 , respectively.

Work-Study Conflict and Work-Study Facilitation. For work-study conflict, we used the 4-item Work-School Conflict Scale (“Because of my job, I go to university tired”); for workstudy facilitation, we used the 5-item Work-School Facilitation Scale ("The skills I use at work are useful for things I have to do at university" (Butler, 2007). Students responded using a 6-point scale that ranged from 1 strongly disagree to 6 strongly agree. Butler (2007) reported alphas of .88 and .85 , and supported validity by finding expected associations with student effort, attendance, and satisfaction. Our alphas were .87 and .83 , respectively.

Job Characteristic Measures. We assessed four characteristics- job demands, job autonomy, workplace support, and workplace climate culture. 
(a) Job demands. Seven items from the Job Demands Scale (Karasek, 1979) tapped effort required, time pressure, and conflicting demands ("In my job, there is never enough time"; 6point scale from 1 hardly ever to 6 very often). Using similar items, Butler (2007) reported an alpha of .81 with students, and, for validity, found that demands were related positively to hours worked and work-study conflict. Alpha in our study was .88.

(b) Job autonomy. Four items from the Decision Authority Scale (Karasek, 1979) assessed level of work autonomy ("I have a lot of say about what happens in my job"; 6-point scale 1 hardly ever to 6 very often). Butler (2007) reported an alpha of .85 with students, and found the scale related positively to work-study facilitation and negatively to conflict. Alpha $=.88$.

(c) Workplace support. The 5-item Support at Work Scale (Zhang, Punnett, Gore, \& CPH-NEW Research Team, 2014) tapped support and respect from supervisors and colleagues ("My supervisor pays attention to what I am saying"; 1 hardly ever to 6 most of the time). Zhang et al. (2014) reported an alpha of .75, and, in support of validity, found job support was associated positively with well-being and negatively with intention to leave. Alpha $=.88$.

(d) Workplace crafting culture. The 6-item Innovation Scale (Zeitz, Johannesson, \& Ritchie, 1997) assessed the level of encouragement for students to job craft ("Where I work, I am encouraged to make suggestions for how to improve my job"; 1 hardly ever to 6 most of the time). Zeitz et al. (1997) reported an alpha of .84, and supported validity by showing that innovative workplace culture was related positively to management support and cohesion at work. Alpha $=.88$.

Person Characteristic Measure. We assessed one characteristic, intrinsic work motivation, using the 6-item Intrinsic Work Motivation Scale (Warr, Cook, \& Wall, 1979; "I 
take pride in doing my job as well as I can"; 1 hardly ever to 6 most of the time). Boxall, Hutchison, and Wassenaar (2015) reported an alpha of .81, and in support of validity found intrinsic motivation to be associated with more skill utilisation and work commitment. Alpha $=.91$.

Study Characteristics Measures. We measured two characteristics - university affect and engagement.

(a) University affect. The 12-item Job Affect Scale (Warr, 1990) was adapted to assess student mood in relation to their studies ("Thinking of the past few weeks, what has been your attitude towards your university studies?"; e.g., relaxed, worried, depressed, uneasy; 1 none of the time to 6 nearly all the time). Two subscales of positive and negative affect have been supported, with alphas $>.80$, and validity evidenced by finding expected correlations with other measures of well-being (Creed et al., 2015). Alphas in our study were .86 and .87, respectively.

(b) University engagement. The 5-item Vigor Subscale from the Utrecht Work Engagement Scale for Students (Schaufeli, Martinez, Pinto, Salanova, \& Bakker, 2002; e.g., "When I get up in the morning, I feel like tackling my university work") was used. Responses were from 1 strongly disagree to 6 strongly agree. Schaufeli et al. (2002) reported acceptable alphas across multiple countries, and supported validity by finding expected correlations with well-being and other engagement measures. Alpha was .83.

\section{Procedure}

The study had ethics approval. Students were recruited via announcements on course websites, campus notice boards, and at lectures, and then directed to an online survey. For participating, they had the opportunity to go into a draw to win a $\$ 50$ shopping voucher.

\section{Analytic Approach}


Latent variable analysis (maximum likelihood; AMOS 24) was used for all analyses. The scales with fewer than six items (i.e., job crafting, work-study conflict, work-study facilitation, autonomy, support, and engagement) were represented by their individual items. The scales with more than 6 items (i.e., job demands, culture, motivation, and affect) were parcelled (3 parcels per scale) by running separate EFAs for each scale, rank-ordering the items by factor loading, and allocating high and low loading items to each parcel (Landis, Beal, \& Tesluk, 2000). Model fit was assessed using $\chi^{2}$ (significant $p$ expected when sample $<250$ and 54 observed variables; Hair, Black, Babin, \& Anderson, 2010), normed chi-square $\left(\chi^{2} / d f<3.0\right.$ considered a good fit $)$, Comparative Fit Index $(\mathrm{CFI} \geqslant .90)$, and Root Mean-Square Error of Approximation (RMSEA <.07). As hours worked was related to work-study conflict $(r=.40, p<.001)$, it was controlled in all analyses.

\section{Results}

The measurement model was a good fit: $\chi^{2}(1282)=1983.99, p<.001, \chi^{2} / d f=1.55, \mathrm{CFI}=.90$, RMSEA $=.05$. There were no cross-loadings of note, all standardised regression weights were significant ( $p<.001$; range .39-.95), and correlations among the latent variables mirrored those for scale totals (see Table 1). The structural model was also a good fit: $\chi^{2}(1306)=2054.25$, $p<.001, \chi^{2} / d f=1.57, \mathrm{CFI}=.90, \mathrm{RMSEA}=.05$. Partially supporting Hypothesis $1 \mathrm{a}$, there were significant paths from job demands $(\beta=.33, p<.001)$, autonomy $(\beta=.22, p=.016)$, and culture ( $\beta=.28, p=.008)$, but not support, to task crafting; from autonomy $(\beta=.23, p=.004)$, but not demands, culture, or support, to cognitive crafting; and from demands $(\beta=.17, p=.016)$ and support $(\beta=.24, p=.006)$, but not autonomy or culture, to relational crafting. Partially supporting Hypothesis $1 \mathrm{~b}$, motivation $(\beta=.43, p<.001)$ was related to cognitive crafting, but not to task or relational crafting. Partially supporting Hypothesis $1 \mathrm{c}$, negative affect $(\beta=.20$, 
$p=.011$ ), but not positive affect or engagement, was related to cognitive crafting; negative affect, positive affect, and engagement were unrelated to task and relational crafting.

There was no support for Hypothesis 2a, as task, cognitive, and relational crafting were unrelated to work-study conflict. There was partial support for Hypothesis $2 \mathrm{~b}$ : cognitive $(\beta=.66, p<.001)$ and relational $(\beta=.25, p<.001)$, but not task crafting, were related to facilitation. Additionally, hours worked $(\beta=.44, p<.001)$ was related to conflict. One anomaly was the relationship between negative affect and cognitive crafting. The bivariate relationship between these two variables was positive, but not significant (Table 1); whereas, the relationship in the structural model was positive, and significant, suggesting that more dissatisfied students were more likely to adjust their thoughts about the job. The significant paths identified in the structural model are reported in Figure 2. Variances accounted for were: $46 \%$ (task crafting), 56\% (cognitive crafting), 25\% (relational crafting), 53\% (facilitation), and $21 \%$ (conflict).

From these analyses, cognitive crafting potentially mediated between autonomy, motivation, and negative affect to facilitation, and relational crafting potentially mediated between demands and support to facilitation. First, to test mediation, the direct paths between the predictors and outcomes were assessed. In this analysis, $\chi^{2}(1296)=2026.29, p<.001$, $\chi^{2} / d f=1.56, \mathrm{CFI}=.90$, and $\mathrm{RMSEA}=.05$, autonomy $(\beta=.26, p=.002)$, motivation $(\beta=.35$, $p<.001)$, and engagement $(\beta=.17, p=.027)$ were related to facilitation, and demands $(\beta=.32$, $p<.001)$ and hours worked $(\beta=.32, p<.001)$ were associated with conflict. These significant direct paths were added to Figure 2.

Next, the indirect paths were assessed (AMOS bootstrapping; 2000 samples) to calculate SEs and $95 \%$ bias-corrected CIs. Mediation occurs when the $95 \%$ CIs of the indirect effect do not include zero (Preacher \& Hayes, 2008). In this model, $\chi^{2}(1290)=1994.88, p<.001$, 
$\chi^{2} / d f=1.55, \mathrm{CFI}=.90, \mathrm{RMSEA}=.05$, cognitive crafting mediated between motivation (CIs .01 to .18) and negative affect (CIs .01 to .12), but not autonomy (-.10 to .12) to facilitation, but relational crafting did not mediate between demands (-.06 to .05) and support (-.03 to .09) to facilitation (note, that while the analysis indicated mediation between negative affect and facilitation, the bivariate correlation between negative affect and cognitive crafting was not significant, suggesting that the mediation could be dependent on extraneous variable/s). Thus, Hypothesis 3 was partially supported. The direct path from motivation to facilitation remained significant $(\beta=.20, p=.024)$, indicating the mediation path via cognitive crafting was partial. The direct path between negative affect and facilitation was not significant in the presence of the mediator, indicating full mediation. The total effect of motivation on facilitation was $20.3 \%$, with $8 \%$ explained by the mediator. The total effect of negative affect on facilitation was $4 \%$.

\section{Discussion}

We found partial support for our hypotheses that job (H1a), person (H1b), and study characteristics (H1c) would be related to student job crafting, and, in turn, job crafting would be related to work-study facilitation (H2b). Job demands, autonomy, and culture (job characteristics) were related to more task crafting; job autonomy (job characteristic), student work motivation (person characteristic), and university-related negative affect (study characteristic) were related to more cognitive crafting; and job demands and job support (job characteristics) were related to higher relational crafting. Thus, job characteristics were related to task and relational crafting, whereas all three characteristics (i.e., job, person, and study) were related to cognitive crafting.

Being triggers to self-regulatory behaviours at work (Bakker \& Demerouti, 2008; Wrzesniewski \& Dutton, 2001), job, person, and study characteristics represent different 
aspects of motivation to job craft. These potentially include "can do" aspects (e.g., "I can do this successfully"), embedded, for example, in person characteristics, "reasons to" aspects (e.g., "Why I should do this"), related to situation demands and cognitive realignments, and "energised to" aspects, which draw on affective states to provide the stimulus (or dampener) and direction for change to improve the situation (Parker, Bindl, \& Strauss, 2010). These underlying motivational distinctions suggest nuanced explanations for individual drivers of proactive engagement in behaviours that manage demands, progress desired goals, and lead to improved satisfactions (cf. Lord et al., 2010). Such a framework could inform counsellors who work with young people who are struggling to manage multiple roles, and should be examined in future research.

A feature of the current study was that it tested two university-related antecedents to job crafting: university affect and study engagement. Negative affect was related to more cognitive crafting, suggesting that the more negative students were about their studies, the more they rethought their role as employees, potentially to make their job more meaningful, important, and satisfying. Negative experiences in one role can be counterbalanced by greater involvement in other roles (Edwards \& Rothbard, 2000). This has been shown to operate in other situations of role conflict (e.g., work-family conflict; Michel et al., 2011), and potentially explains this relationship in student workers. While such an approach might improve students' immediate situation, the downside is that counterbalancing in this way might operate against their long-term interests if it is part of a process of disengaging from or downplaying their role as a student. Future research might examine the effect on students of counterbalancing, and test whether it operates in both directions - from study to work, as suggested here, as well as from work to study. 
The university-related antecedents of positive affect and student engagement, despite having bivariate correlations with aspects of job crafting, were unrelated to job crafting when tested with the other predictors. Previous research has suggested that work-based, positive affect is related to job crafting, for example, by employers being more productively engaged with colleagues and supervisors and creating new activities that better suit their occupational needs (e.g., Tims et al., 2012). Adults with more positive affect have been shown to build a wider repertoire of personal resources to apply to managing their environment (Demerouti \& Bakker, 2014), as predicted by the broaden-and-build theory (Fredrickson, 2001). It might be that positive mood for study activities increases study motivation and focus, and reduces work orientation and relevance, leaving job crafting a side issue in the student's life. Future studies might assess other aspects of positive affect with students, such as work-based or general positive affect.

In relation to study engagement, activities carried out in one domain can influence affect and behaviour (i.e., "spillover") in a second domain (Edwards \& Rothbard, 2000; McNall, Nicklin, \& Masuda, 2010). That we did not find study engagement and positive affect to be related to job crafting might mean that happy and engaged students give priority to their studies and see their job as less important, and so do not expend energy improving their work situation. Thus, while there was some support for these study-related variables, other studyrelated variables need to be assessed, as this should lead to a better understanding of factors that influence students' approaches to managing their job roles.

Not all characteristics (i.e., job, person, and study) were related to all aspects of job crafting (i.e., task, cognitive, and relational). Previous research also has identified differential relationships between job crafting antecedents and measures of job crafting (Kanten, 2014; Petrou et al., 2016), suggesting that drivers of job crafting might be different in different 
workplaces and populations, and that some characteristics might have indirect effects or interact with other variables when relating to job crafting (Le Blanc et al., 2017). We confirmed that job and person characteristics were related to job crafting, and also found support for a relationship with a non-work characteristic (negative feelings about university).

Partially supporting Hypothesis $2 \mathrm{~b}$, cognitive and relational (but not task) crafting were related to work-study facilitation. Also, partially supporting Hypothesis 3, cognitive crafting mediated the relationships from job motivation (partially) and negative affect (fully) to facilitation. This suggests that developing a construction of work as meaningful and positive and developing work relationships facilitate functioning in the study domain, indicating that students can benefit from job crafting. For example, improved affect from job crafting should improve mood generally and give students a more positive focus on their life and studies (Greenhaus \& Powell, 2006).

Additionally, more job autonomy, job motivation, and study engagement were related directly to facilitation, suggesting that demands and resources might also operate via other pathways to influence facilitation. For example, more autonomy in the job might facilitate studying while at work, thereby facilitating study, whereas students who are more intrinsically motivated to work might be more energised (i.e., less exhausted) and be better able to manage/recover from their work responsibilities in order to engage with study. Engagement in roles away from work appears to alter the perception of workers (Kelly et al., 2008), implying that students who are more engaged in their study might downplay the value of work, allowing them to recover faster and redirect their attention back to study.

We found no support for the hypothesis that task crafting is related to facilitation, nor did we find support for the relationships between task, cognitive, and relational crafting and work-study conflict (H2a) over and above the effect of number of hours worked. Regarding 
task crafting, one explanation is that part-time student workers, who have little power at their workplace, and who work in routinized occupations (Australian Government, 2018), might have insufficient authority to change work tasks, or the changes might not materially alter the work being done sufficiently to have a spill-over effect on their study role. Similarly, students, who, by-and-large, are intelligent and socially adept (Hsiao, Baum, \& Teng, 2009) might be able to gain from their work experiences, and thereby facilitate activities related to study, by changing the way they see work and by benefitting from their social interactions, but these experiences might still be insufficient to reduce the role conflict between their job and study. Developing and persisting with job crafting strategies seems to be important because this aids facilitation, but future research needs to identify those activities and strategies that might assist students ameliorate conflict between the two roles.

\section{Limitations}

First, the study was limited by being cross-sectional, and while based on theoretical process models, the relationships need to be tested longitudinally so that stronger causal statements can be made by examining reverse and reciprocal relationships. Second, a limited range of demands/resources was assessed and other antecedents to job crafting need to be examined. A wide range has been tested in adults, including organisational and person-based variables (e.g., Demerouti \& Bakker, 2014), and others need to be examined for students. Related to this, we only assessed the direct relationships between job, person, and study characteristics and job crafting, when understanding interactions among these antecedents and other third variables (e.g., need to work) will potentially increase our understanding of what drives crafting in working students. Third, the study did not examine group differences (e.g., gender, SES), so it is not known which students face which problems and use what strategies to manage this interface. Future research needs to tease this out. Fourth, the study 
did not assess relationships between job crafting and other important study variables (e.g., grade, attendance), and these need to be assessed. Fifth, we noted that in the model, negative affect was related to more cognitive crafting, when these two variables were not bivariately correlated. Previous studies have found higher negative affect to be related to more job crafting (Heuvel, Demerouti, \& Peeters, 2015), and future research needs to confirm this relationship in other student samples. Finally, there is little information on the specific strategies that students employ to manage their job-study fit. Determining these strategies will assist in developing interventions to improve both work and study functioning, as job crafting interventions have improved confidence, well-being, and access to resources in adults (Van den Heuvel, Demerouti, \& Peeters, 2012; cited in Demerouti, 2014)

\section{Practical implications}

Job crafting can lead to improved job fit for individuals, with likely flow-on effects for work- and non-work-related well-being and performance, as indicated by job crafting research generally (Rudolph et al., 2017; Wang et al., 2016) and suggested by the current study. This can be especially important for students, as study demands change dramatically over the semester and year (vis-à-vis assignments and exams). Job crafting by students depends largely on them being able to marshal personal, social, and organisational resources so they can modify their environment or perceptions of their environment. This process was characterised as the students drawing on self-regulatory strengths to help reduce perceived discrepancies between actual and desired situations (cf. Bandura, 1991). For students, being proactive at their workplace to modify tasks, explore the meaning of their work, and build relational networks is likely to assist them with their job and make it more satisfying; it is also likely to benefit them by facilitating aspects of their study and life as a student. 
The development of job crafting skills for these part-time jobs might also carry-over to later full-time employment and influence career progress, and, thus, can be considered in the light of individual career development. Universities have many reasons (e.g., financial, commitment to students) to reduce drop-out and poor performance, and developing job crafting capabilities in their student body has the potential to contribute to this. This skills development could occur through standard educational practices (e.g., career courses, course add-ons), specifically targeted workshops, and via counselling services. Organisations who employ students need to acknowledge that students will want to job craft. They should structure their jobs so there is room for crafting and engage with them about it so both parties benefit, and potential downsides (e.g., safety) are reduced. Student job crafting has the potential to benefit all parties, but especially the students who now largely must work to fund their education.

\section{References}

Adebayo, D. O. (2006). Workload, social support, and work-school conflict among Nigerian nontraditional students. Journal of Career Development, 33, 125-141. doi:10.1177/0894845306289674

Adebayo, D. O., Sunmola, A. M., \& Udegbe, I. B. (2008). Subjective wellbeing, work-school conflict and proactive coping among Nigerian non-traditional students. Career Development International, 13, 440-455. doi:10.1108/13620430810891464

Akkermans, J., \& Tims, M. (2017). Crafting your career: How career competencies relate to career success via job crafting. Applied Psychology, 66, 168-195. doi:10.1111/apps.12082

Aust, B., Rugulies, R., Finken, A., \& Jensen, C. (2010). When workplace interventions lead to negative effects. Scandinavian Journal of Public Health, 38, 106-119. doi:10.1177/1403494809354362 
Australian Government (2019), "Study in Australia”. Retrieved from https://www.studyinaustralia.gov.au/

Bakker, A. B., \& Demerouti, E. (2007). The job demands-resources model. Journal of Managerial Psychology, 22, 309-328. doi:10.1108/02683940710733115

Bakker, A. B., Tims, M., \& Derks, D. (2012). Proactive personality and job performance. Human Relations, 65, 1359-1378. doi:10.1177/0018726712453471

Bandura, A. (1991). Social cognitive theory of self-regulation. Organizational Behavior and Human Decision Processes, 50, 248-287. doi:10.1016/0749-5978(91)90022-L

Berg, J. M., Grant, A. M., \& Johnson, V. (2010). When callings are calling. Organization Science, 21, 973-994. doi:10.1287/orsc.1090.0497

Boxall, P., Hutchison, A., \& Wassenaar, B. (2015). How do high-involvement work processes influence employee outcomes? The International Journal of Human Resource Management, 26, 1737-1752. doi:10.1080/09585192.2014.962070

Butler, A. B. (2007). Job characteristics and college performance and attitudes. Journal of Applied Psychology, 92, 500-510. doi:10.1037/0021-9010.92.2.500

Butler, A. B., Dodge, K. D., \& Faurote, E. J. (2010). College student employment and drinking. Journal of Occupational Health Psychology, 15, 291-303. doi:10.1037/a0019822

Creed, P. A., French, J., \& Hood, M. (2015). Working while studying at university. Journal of Vocational Behavior, 86, 48-57. doi:10.1016/j.jvb.2014.11.002

Curtis, S., \& Shani, N. (2002). The effect of taking paid employment during term-time on students' academic studies. Journal of Further and Higher Education, 26, 129-138. doi:10.1080/03098770220129406 
Demerouti, E. (2014). Design your own job through job crafting. European Psychologist, 19, 237-247. doi:10.1027/1016-9040/a000188

Demerouti, E., \& Bakker, A. B. (2014). Job crafting, in M. C. Peeters, J. de Jonge, \& T. W. Taris (Eds.), An introduction to contemporary work psychology (pp. 414-433). New York, NY: John Wiley \& Sons.

Derous, E., \& Ryan, A. M. (2008). When earning is beneficial for learning. Journal of Vocational Behavior, 73, 118-131. doi:10.1016/j.jvb.2008.02.003

Devlin, M., James, R., \& Grigg, G. (2008). Studying and working. Tertiary Education and Management, 14, 111-122. doi:10.1080/13583880802053044

Edwards, J. R., \& Rothbard, N. P. (2000). Mechanisms linking work and family. Academy of Management Review, 25, 178-199. doi:10.2307/259269

Fredrickson, B. L. (2001). The role of positive emotions in positive psychology. American Psychologist, 56, 218-226. doi:10.1037//0003-066X.56.3.218

Geel, R., \& Backes-Gellner, U. (2012). Earning while learning. Labour, 26, 313-340. doi:10.1111/j.1467-9914.2012.00548.x

Giancola, J. K., Grawitch, M. J., \& Borchert, D. (2009). Dealing with the stress of college. Adult Education Quarterly, 59, 246-263. doi:10.1177/0741713609331479

Greenhaus, J. H., \& Powell, G. N. (2006). When work and family are allies. Academy of Management Review, 31, 72-92. doi:10.1111/cns.13067

Hair, J., Black, W., Babin, B., \& Anderson, R. (2010). Multivariate data analysis. Hoboken, NJ: Pearson Education.

Heuvel, M., Demerouti, E., \& Peeters, M. C. (2015). The job crafting intervention: Effects on job resources, self-efficacy, and affective well-being. Journal of Occupational and Organizational Psychology, 88, 511-532. doi:10.1111/joop.12128 
Hsiao, S., Baum, T., \& Teng, C. (2009). Employing student workers in the hotel industry on a part-time basis, in International CHRIE Conference-Refereed Track, p.11.

Ilies, R., Pater, I. E., Lim, S., \& Binnewies, C. (2012). Attributed causes for work-family conflict. Organizational Psychology Review, 2, 293-310. doi:10.1177/2041386612452288

Kanten, P. (2014). The antecedents of job crafting. European Journal of Business and Social Sciences, 3, 113-128. Retrieved from http://ejbss.com/home.aspx

Karasek, R. A. (1979). Job demands, job decision latitude, and mental strain. Administrative Science Quarterly, 24, 285-308. doi:10.2307/2392498

Kelly, E. L., Kossek, E. E., Hammer, L. B., Durham, M., Bray, J., Chermack, K., ... \& Kaskubar, D. (2008). Getting there from here. Academy of Management Annals, 2, 305349. doi:10.1080/19416520802211610

Kooij, D. T., Tims, M., \& Kanfer, R. (2015). Successful aging at work. In P. Bal, D. Kooij, \& D. Rousseau (Eds.), Aging workers and the employee-employer relationship (pp. 145161). New York, NY: Springer.

Le Blanc, P. M., Demerouti, E., \& Bakker, A. B. (2017). How can I shape my job to suit me better? Job crafting for sustainable employees and organisations. In N, Chmiel, F. Fraccaroli, \& M. Sverke (Eds.). An introduction to work and organizational psychology: An international perspective (pp. 48-63). Hoboken, NJ: John Wiley \& Sons.

Landis, R. S., Beal, D. J., \& Tesluk, P. E. (2000). A comparison of approaches to forming composite measures in structural equation models. Organizational Research Methods, 3, 186-207. doi:10.1177/109442810032003

Lin, Y. S., Huang, W. S., Yang, C. T., \& Chiang, M. J. (2014). Work-leisure conflict and its associations with well-being. Tourism Management, 45, 244-252. doi:10.1016/j.tourman.2014.04.004 
Lingard, H. (2007). Conflict between paid work and study? Journal for Education in the Built Environment, 2, 90-109. doi:10.11120/jebe.2007.02010090

Lingard, H. (2012). Balancing study and paid work. Construction Economics and Building, 5, 41-47. doi:10.1080/0144341940140306

Lord, R. G., Diefendorff, J. M., Schmidt, A. M., \& Hall, R. J. (2010). Self-regulation at work. Annual Review of Psychology, 61, 543-568. doi:10.1146/annurev.psych.093008.100314

McNall, L. A., \& Michel, J. S. (2011). A dispositional approach to work-school conflict and enrichment. Journal of Business and Psychology, 26, 397-411. doi:10.1007/s10869-0109187-0

McNall, L. A., Nicklin, J. M., \& Masuda, A. D. (2010). A meta-analytic review of the consequences associated with work-family enrichment. Journal of Business and Psychology, 25, 381-396. doi:10.1007/S10869-009-9141-1

Michel, J. S., Kotrba, L. M., Mitchelson, J. K., Clark, M. A., \& Baltes, B. B. (2011). Antecedents of work-family conflict. Journal of Organizational Behavior, 32, 689-725. doi:10.1002/job.695

OECD. (2008). Education at a glance 2008. Retrieved from http://www.oecd.org/home Park, Y., \& Sprung, J. M. (2013). Work-school conflict and health outcomes. Journal of Occupational Health Psychology, 18, 384-394. doi:10.1037/a0033614

Park, Y., \& Sprung, J. M. (2015). Weekly work-school conflict, sleep quality, and fatigue. Journal of Organizational Behavior, 36, 112-127. doi:10.1002/job.1953

Parker, S. K., Bindl, U. K., \& Strauss, K. (2010). Making things happen. Journal of Management, 36, 827-856. doi:10.1177/0149206310363732 
Peeters, M., Wattez, C., Demerouti, E., \& de Regt, W. (2009). Work-family culture, workfamily interference and well-being at work. Career Development International, 14, 700713. doi: $10.1108 / 13620430911005726$

Petrou, P., \& Bakker, A. B. (2016). Crafting one's leisure time in response to high job strain. Human Relations, 69, 507-529. doi:10.1177/0018726715590453

Petrou, P., Demerouti, E., \& Xanthopoulou, D. (2016). Regular versus cutback-related change. International Journal of Stress Management, 24, 62-85. doi:10.1037/str0000033

Polidano, C., \& Zakirova, R. (2011). Outcomes from combining work and tertiary study. Adelaide, AU: National Centre for Vocational Education Research.

Preacher, K. J., \& Hayes, A. F. (2008). Asymptotic and resampling strategies for assessing and comparing indirect effects in multiple mediator models. Behavior Research Methods, 40, 879-891. doi:10.3758/BRM.40.3.879

Quintini, G. (2015). Working and learning. OECD Social, Employment and Migration Working Paper. doi:10.1787/5jrw4bz6hl43-en

Rudolph, C. W., Katz, I. M., Lavigne, K. N., \& Zacher, H. (2017). Job crafting: A metaanalysis of relationships with individual differences, job characteristics, and work outcomes. Journal of Vocational Behavior, 102, 112-138. doi:10.1016/j.jvb.2017.05.008

Schaufeli, W. B., Martinez, I. M., Pinto, A. M., Salanova, M., \& Bakker, A. B. (2002). Burnout and engagement in university students. Journal of Cross-Cultural Psychology, 33, 464-481. doi:10.1177/0022022102033005003

Sekiguchi, T. (2012). Part-time work experience of university students and their career development. Japan Labor Review, 9, 5-29. Retrieved from https://www.jil.go.jp/english/JLR/index.html 
Singla, N. (2013). Blending work and school. Doctoral dissertation, University of South Florida. Retrieved from http://scholarcommons.usf.edu/etd/4582

Slemp, G. R. \& Vella-Brodrick, D. A. (2014). Optimising employee mental health. Journal of Happiness Studies, 15, 957-977. doi:10.1007/s10902-013-9458-3

Slemp, G. R., Kern, M. L., \& Vella-Brodrick, D. A. (2015). Workplace well-being. Psychology of Well-Being, 5, 1-17. doi:10.1186/s13612-015-0034-y

Sturges, J. (2012). Crafting a balance between work and home. Human Relations, 65, 15391559. doi:10.1177/0018726712457435

Sy, S. R. (2006). Family and work influences on the transition to college among Latina adolescents. Hispanic Journal of Behavioral Sciences, 28, 368-386. doi:10.1177/0739986306290372

Taylor, G., Lekes, N., Gagnon, H., Kwan, L., \& Koestner, R. (2012). Need satisfaction, work-school interference and school dropout. British Journal of Educational Psychology, 82, 622-646. doi:10.1111/j.2044-8279.2011.02050.x

Tims, M., Bakker, A. B., \& Derks, D. (2012). Development and validation of the Job Crafting Scale, Journal of Vocational Behavior, 80, 173-186. doi:10.1016/j.jvb.2011.05.009

Tims, M., Bakker, A. B., \& Derks, D. (2014). Daily job crafting and the self-efficacyperformance relationship. Journal of Managerial Psychology, 29, 490-507. doi:10.1108/JMP-05-2012-0148

Van den Heuvel, M., Demerouti, E., \& Peeters, M. C. (2012). Successful job crafting through group training. In J. de Jonge, M. C. Peeters, S. Sjollema, \& H. de Zeeuw (Eds.). Sharp at work (pp. 7-20). Rotterdam, ND: Gorcum. 
Vossensteyn, H., Kottmann, A., Jongbloed, B., Kaiser, F., Cremonini, L., Stensaker, B., ... \& Wollscheid, S. (2015). Dropout and completion in higher education in Europe. Retrieved from http://doc.utwente.nl/98513/1/dropout-completion-he_en.pdf

Wang, H., Demerouti, E., \& Bakker, A. B. (2016). A review of job crafting research. In S. Parker, \& U. Bindl (Eds.). Proactivity at work (pp. 95-122). New York, NY: Routledge. Warr, P. (1990). The measurement of well-being and other aspects of mental health. Journal of Occupational Psychology, 63, 193-210. doi:10.1111/j.2044-8325.1990.tb00521.x

Warr, P., Cook, J., \& Wall, T. (1979). Scales for the measurement of some work attitudes and aspects of psychological well-being. Journal of Occupational Psychology, 52, 129-148. doi:10.1111/j.2044-8325.1979.tb00448.x

Wyland, R., Lester, S. W., Ehrhardt, K., \& Standifer, R. (2016). An examination of the relationship between the work-school interface, job satisfaction, and job performance. Journal of Business and Psychology, 31, 187-203. doi:10.1007/s10869-015-9415-8

Wrzesniewski, A., \& Dutton, J. E. (2001). Crafting a job: Revisioning employees as active crafters of their work. The Academy of Management Review, 26, 179-201. doi:10.5465/AMR.2001.4378011

Zeitz, G., Johannesson, R., \& Ritchie, J. E. (1997). An employee survey measuring total quality management practices and culture. Group \& Organization Management, 22, 414444. doi: $10.1177 / 1059601197224002$

Zhang, Y., Punnett, L., Gore, R., \& CPH-NEW Research Team. (2014). Relationships among employees' working conditions, mental health, and intention to leave in nursing homes. Journal of Applied Gerontology, 33, 6-23. doi:10.1177/0733464812443085 
Table 1

Summary Data, Zero-Order Correlations (Above Diagonals) and Correlations among Latent Variables (Below Diagonal); $N=233$.

\begin{tabular}{|c|c|c|c|c|c|c|c|c|c|c|c|c|c|c|c|c|}
\hline Variable & $M$ & $S D$ & $\alpha$ & 1 & 2 & 3 & 4 & 5 & 6 & 7 & 8 & 9 & 10 & 11 & 12 & 13 \\
\hline 1. W-S conflict & 15.13 & 4.60 & .87 & 1 & -.13 & -.01 & -.08 & .04 & $.38 * * *$ & -.07 & -.09 & $-.16^{*}$ & $-.18 * *$ & $-.14 *$ & $-.17 *$ & .12 \\
\hline 2. W-S facilitation & 18.63 & 4.94 & .83 & $-.13^{*}$ & 1 & $.23 * * *$ & $.54 * * *$ & $.36^{* * *}$ & .01 & $.42 * * *$ & $.39 * * *$ & $.41 * * *$ & $.51 * * *$ & $.31 * * *$ & $.27 * * *$ & -.04 \\
\hline 3. Task crafting & 20.91 & 4.04 & .73 & -.02 & $.26^{* *}$ & 1 & $.41 * * *$ & $.36^{* * *}$ & $.23 * * *$ & $.39 * * *$ & $.35 * * *$ & $.49 * * *$ & $.43 * * *$ & $.16^{*}$ & $.20 * *$ & -.03 \\
\hline 4. Cognitive crafting & 17.30 & 5.36 & .85 & -.08 & $.63 * * *$ & $.46^{* * *}$ & 1 & $.27 * * *$ & .07 & $.43 * * *$ & $.37 * * *$ & $.46^{* * *}$ & $.55 * * *$ & $.26^{* * *}$ & $.26 * * *$ & .06 \\
\hline 5. Relational crafting & 20.15 & 4.81 & .80 & .04 & $.40^{* * *}$ & $.43 * * *$ & $.29 * * *$ & 1 & .11 & $.24 * * *$ & $.41 * * *$ & $.29 * * *$ & $.30 * * *$ & $.15^{*}$ & $.23 * * *$ & -.04 \\
\hline 6. Job demands & 29.43 & 6.87 & .88 & $.38 * * *$ & .06 & $.34 * * *$ & .11 & $.16^{*}$ & 1 & -.07 & -.10 & .07 & -.03 & -.03 & -.12 & $.17 * *$ \\
\hline 7. Job autonomy & 15.43 & 4.96 & .88 & -.07 & $.52 * * *$ & $.46^{* * *}$ & $.50^{* * *}$ & $.25 * * *$ & -.06 & 1 & $.37 * * *$ & $.49 * * *$ & $.45^{* * *}$ & $.24 * * *$ & $.23 * *$ & -.07 \\
\hline 8. Job support & 23.04 & 5.00 & .88 & $-.16^{*}$ & $.38 * * *$ & $.32 * * *$ & $.40 * * *$ & $.39 * * *$ & -.04 & $.37 * * *$ & 1 & $.49 * * *$ & $.47 * * *$ & $.19^{* *}$ & $.25 * * *$ & -.11 \\
\hline 9. Job culture & 22.80 & 6.51 & .88 & $-.19 *$ & $.48 * * *$ & $.56^{* * *}$ & $.54 * * *$ & $.38 * * *$ & .12 & $.56^{* * *}$ & $.53 * * *$ & 1 & $.50 * * *$ & $.23 * * *$ & $.33 * * *$ & .01 \\
\hline 10. Job motivation & 28.53 & 5.76 & .91 & $-.20 * *$ & $.57 * * *$ & $.47 * * *$ & $.63^{* * *}$ & $.38^{* * *}$ & .05 & $.51 * * *$ & $.50 * * *$ & $.57 * * *$ & 1 & $.22 * *$ & $.29 * * *$ & -.11 \\
\hline 11. Study engagement & 17.65 & 4.56 & .84 & $-.16^{*}$ & $.35 * * *$ & $.19^{*}$ & $.26^{* * *}$ & .11 & -.02 & $.24 * * *$ & $.21 * *$ & $.26^{* * *}$ & $.22 * *$ & 1 & $.40 * * *$ & $-.14 *$ \\
\hline 12. Positive affect & 22.60 & 5.74 & .87 & $-.18 *$ & $.30 * * *$ & $.22 * *$ & $.28 * * *$ & $.19 * *$ & -.14 & $.25 * * *$ & $.26 * * *$ & $.37 * * *$ & $.32 * * *$ & $.48 * * *$ & 1 & $-.46^{* * *}$ \\
\hline 13. Negative affect & 15.12 & 6.19 & .88 & .13 & -.04 & -.03 & .08 & .01 & $.16^{*}$ & -.09 & -.11 & .02 & -.10 & $-.16^{*}$ & $-.52 * * *$ & 1 \\
\hline
\end{tabular}

Note. ${ }^{*} p<.05 ; * * p<.01 ; * * * p<.001$ 


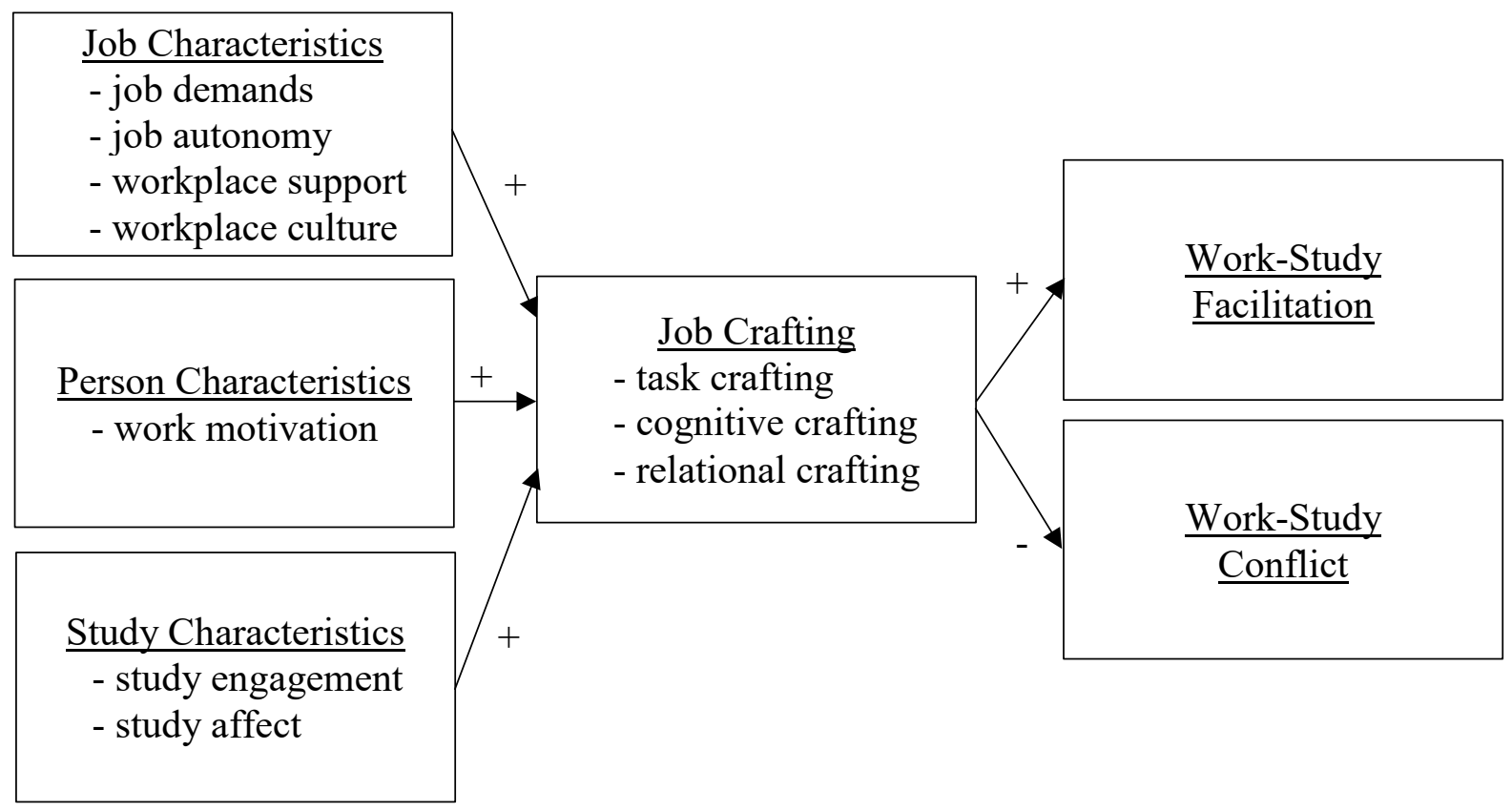

Figure 1. Proposed model: job (demands, autonomy, support, culture), person (motivation), and study characteristics (engagement, affect) are related to work-study facilitation and workstudy conflict via job crafting. 


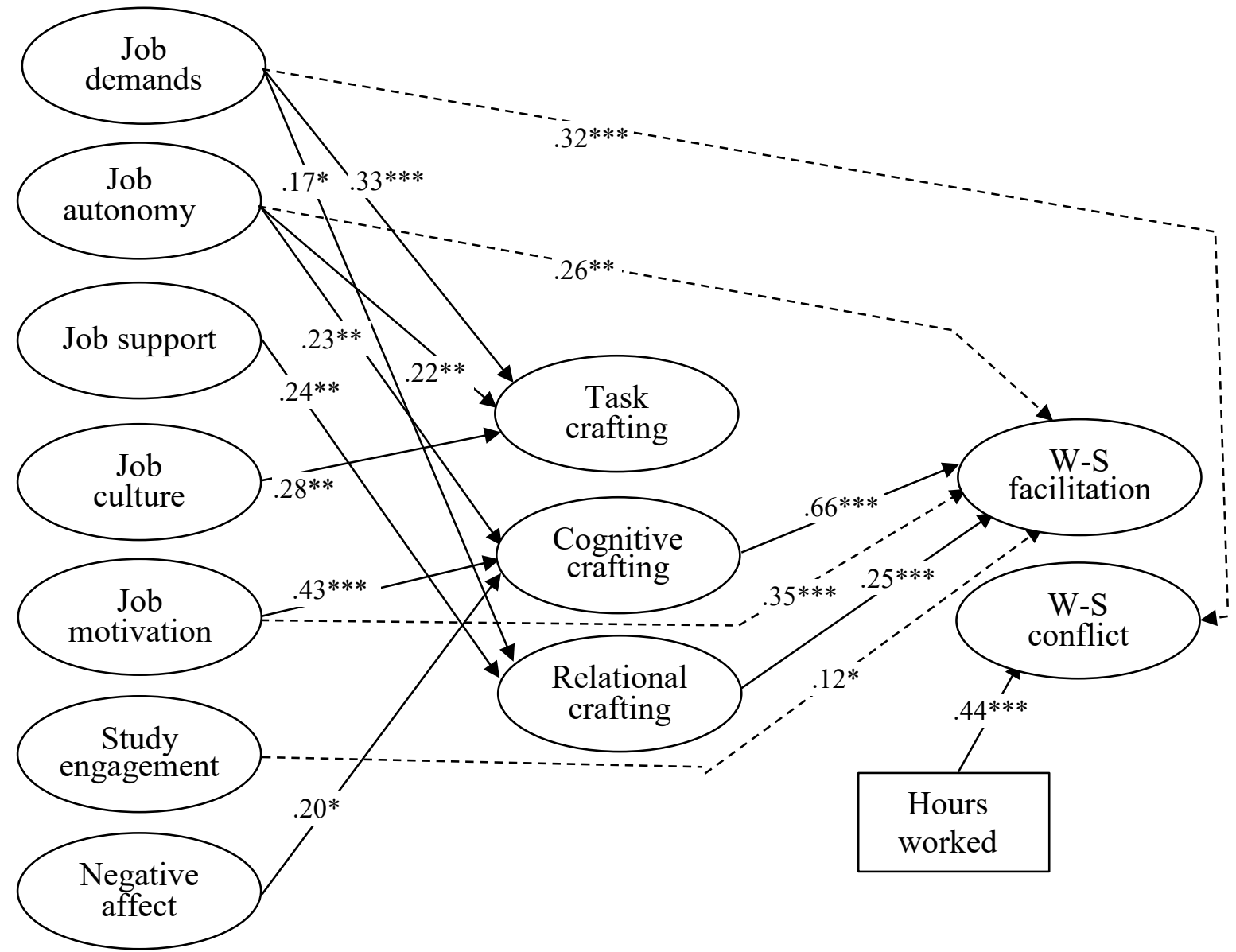

Figure 2. Standardised regression paths. Solid lines result from testing hypothesised model; dashed lines are direct effects. Standardised beta weights are reported. 